\title{
Kepuasan Pemangku Kepentingan pada Layanan Manajemen Kelembagaan di Fakultas Penyelenggara Pendidikan Swasta
}

\author{
*Saiful Prayogi, Agus Muliadi, Baiq Asma Nufida
}

Fakultas Sains Teknik dan Terapan, Universitas Pendidikan Mandalika, J1 Pemuda 59A

Mataram, Indonesia

Corresponding email: saifulprayogi@undikma.ac.id

\section{Sejarah Artikel}

Dikirim: September 2021

Diterima: November 2021

Dipublikasi: Desember 2021

\section{Kata Kunci}

Kepuasan layanan; Pemangku kepentingan; Layanan pendidikan; Sumber daya manusia; Kerjasama

\begin{abstract}
Abstrak
Penelitian ini bertujuan untuk mengeksplorasi kepuasan pemangku kepentingan pada layanan manajemen kelembagaan di Fakultas Sains, Teknik, dan Terapan, (FSTT) Universitas Pendidikan Mandalika. Pemangku kepentingan yang dimaksud adalah pihak internal dan eksternal. Layanan managemen kelembagaan difokuskan pada aspek kepuasan layanan pendidikan mahasiswa, kepuasan sumber daya dosen dan tenaga kependidikan, dan kepuasan mitra kerjasama. Penelitian ini merupakan penelitian survey dimana data dikumpulkan menggunakan kuesioner yang berisi item pernyataan kepuasan layanan pada pemangku kepentingan. Kuesioner divalidasi oleh validator ahli agar dapat digunakan untuk mengukur tingkat kepuasan pemangku kepentingan. Kuesioner kepuasan layanan pendidikan diberikan kepada mahasiswa yang sedang aktif kuliah, kuesioner kepuasan layanan sumber manusia diberikan kepada dosen dan tenaga kependidikan, dan kepuasan layanan kerjasama diberikan kepada mitra kerjasama. Tiap-tiap data layanan kepuasan dianalisis secara deskriptif untuk mengetahui tingkat kepuasan pemangku kepentingan. Hasil studi lebih lanjut disajikan pada artikel ini.
\end{abstract}

\section{Stakeholder Satisfaction in Institutional Management Services at the Faculty of Private Education Providers}

\section{Article History}

Received: September 2021

Accepted: November 2021

Published: December 2021

\section{Key Words}

Service satisfaction;

Stakeholders;

Education services;

Human Resources;

Cooperation

How to cite this article?

\begin{abstract}
This study aims to explore stakeholder satisfaction on institutional management services at the Faculty of Science, Engineering, and Applied, (FSTT) Mandalika University of Education. The stakeholders in question are internal and external parties. Institutional management services are focused on aspects of student education service satisfaction, lecturer and education staff resource satisfaction, and cooperation partner satisfaction. This research is a survey research in which data is collected using a questionnaire containing statements of service satisfaction to stakeholders. The questionnaire was validated by an expert validator so that it can be used to measure the level of stakeholder satisfaction. Education service satisfaction questionnaires are given to students who are actively studying, human resource service satisfaction questionnaires are given to lecturers and education staff, and cooperation service satisfaction is given to cooperation partners. Each service satisfaction data was analyzed descriptively to determine the level of stakeholder satisfaction. Further study results are presented in this article.
\end{abstract}

Prayogi, S., Muliadi, A., \& Nufida, B. (2021). Kepuasan Pemangku Kepentingan pada Layanan Manajemen Kelembagaan di Fakultas Penyelenggara Pendidikan Swasta. Lensa: Jurnal Kependidikan Fisika, 9(2), 184-191. doi:https://doi.org/10.33394/j-1kf.v9i2.4837

\section{PENDAHULUAN}

Pendidikan adalah sektor jasa yang saat ini berkembang sangat pesat di Indonesia, hal ini dapat dilihat dari banyaknya institusi pendidikan pada level universitas yang 
bermunculan baik institusi negeri maupun swasta. Pemerintah Indonesia melalui Kementerian Riset Teknologi dan Pendidikan Tinggi mendukung upaya masyarakat dalam mendirikan Institusi Pendidikan Tinggi dan menguatkan yang sudah ada, ini sebagai upaya untuk mendongkrak pembangunan sumber daya manusia berkelanjutan di Indonesia. Pengembangan pada sektor pendidikan juga penting untuk pengetahuan pribadi, pencapaian karir serta peningkatan status dalam organisasi dan komunitas (Lee et al., 2012). Universitas memainkan peran kunci dalam melatih sumber daya manusia yang menguntungkan untuk pencapaian tujuan pembangunan (World Bank, 2010a). Namun, berkurangnya dana publik, privatisasi, peningkatan pendaftaran siswa dan ekspansi yang cepat mengancam kapasitas universitas untuk memenuhi mandat inti ini (Johnstone, 2009). Dihadapkan dengan kendala-kendala ini, ada kekhawatiran bahwa universitas tidak memberikan layanan yang memuaskan yang memfasilitasi pengembangan lulusan yang kompetitif (UNESCO, 2014). Di satu sisi, universitas sangat ditekan oleh para pemangku kepentingan untuk mengejar keunggulan dalam layanan pendidikan dengan tujuan akhir untuk memastikan bahwa pelanggan, termasuk siswa, adalah puas (World Bank, 2010b). Kualitas layanan dalam pendidikan tinggi digambarkan sebagai ukuran seberapa baik lembaga pendidikan tinggi sesuai dengan kebutuhan dan harapan pelanggan (Govender et al, 2012). Dib dan Alnazer (2013) mengakui bahwa tujuan akhir dari menyediakan layanan berkualitas adalah untuk memastikan bahwa pelanggan puas dengan pengalaman layanan dan penyedia layanan.

Pesatnya perkembangan pendidikan tinggi telah menyebabkan persaingan sengit untuk merebut pangsa pasar. Oleh karena itu, lembaga pendidikan tinggi harus mulai mencari cara yang efektif untuk menarik dan mempertahankan hubungan yang lebih kuat dengan pebelajar (Hasan et al., 2009), selain itu yang paling utama adalah bentuk pelayanan yang diberikan kepada mahasiswa. Universitas sebagai institusi layanan harus menyediakan layanan dalam pendidikan berkualitas, dan memenuhi kebutuhan dan keinginan konsumen, antara lain layanan akademik maupun non akademik (Firdaus, 2005). Bentuk layanan akademik di pendidikan tinggi sering menekankan pada aspek kualitas dosen, sumber daya pengajaran, mekanisme pengajaran, penilaian, dan keterlibatan pebelajar (Seng \& Ling, 2013). Karena ada banyak layanan akademik yang harus disediakan, maka harus melibatkan beberapa elemen yang diharapkan memiliki komitmen dan kualitas tinggi. Kualitas adalah kondisi dinamis yang memengaruhi produk, layanan, orang, proses, dan lingkungan yang memenuhi atau melampaui harapan (Goetsch \& Davis, 2013).

Sistem pendidikan yang bermutu tentunya berkaitan erat dengan kualitas sumber daya manusia. Hal ini didasarkan pada realitas bahwa output (keluaran) dari sistem pendidikan adalah sumber daya manusia yang akan digunakan dalam industri dan pembangunan di suatu daerah. Upaya peningkatan kualitas sumber daya manusia dapat dilakukan dengan perbaikan sistem pendidikan yang selanjutnya dapat menghasilkan sistem pendidikan yang bermutu. Indikator yang dapat digunakan untuk mengukur mutu suatu produk atau jasa adalah kemampuannya dalam memenuhi kriteria yang ditetapkan oleh pelanggan/pemakai. Kriteria yang ditetapkan oleh pelanggan atau pemakai produk/jasa sering juga disebut dengan harapan pelanggan/pemakai. Hasil evaluasi antara harapan (perception) terhadap kualitas layanan dengan kinerja kualitas layanan yang dirasakan (perceived) oleh penggunan layanan (konsumen/pelanggan) disebut sebagai kepuasan. Kepuasan bersifat individual karena setiap individu memiliki tingkat kepuasan yang berbeda-beda sesuai dengan harapannya. Hansemark dan Albinsson (2004) menggambarkan kepuasan sebagai sikap pelanggan secara keseluruhan terhadap penyedia layanan, atau reaksi emosional terhadap perbedaan antara apa yang diantisipasi pelanggan dan apa yang mereka terima dalam hal kualitas layanan yang diberikan. 
Pelanggan di universitas termasuk orang tua, siswa, staf, komunitas, agen pendanaan dan pemberi kerja. Namun, mahasiswa telah diidentifikasi sebagai pelanggan utama di universitas (Karami \& Olfati, 2012; Firdaus, 2006). Selain itu, layanan optimal harus diberikan pada pemangku kepentingan selain mahasiswa, yaitu dosen dan tenaga kependidikan, serta mitra kerjasama. Tiga aspek ini adalah komponen penting dalam penyelenggaraan tri dharma perguruan tinggi.

\section{METODE}

Penelitian ini bertujuan untuk mengeksplorasi kepuasan pemangku kepentingan pada layanan manajemen kelembagaan di Fakultas Sains, Teknik, dan Terapan, (FSTT) Universitas Pendidikan Mandalika. Pemangku kepentingan yang dimaksud adalah pihak internal dan eksternal. Layanan managemen kelembagaan difokuskan pada aspek kepuasan layanan pendidikan, kepuasan sumber daya dosen dan tenaga kependidikan, dan kepuasan mitra kerjasama. Penelitian ini merupakan penelitian survey dimana data dikumpulkan menggunakan kuesioner yang berisi item pernyataan kepuasan layanan pada pemangku kepentingan. Kuesioner divalidasi oleh validator ahli agar dapat digunakan untuk mengukur tingkat kepuasan pemangku kepentingan. Kuesioner kepuasan layanan pendidikan diberikan kepada mahasiswa yang sedang aktif kuliah, kuesioner kepuasan layanan sumber daya manusia diberikan kepada dosen dan tenaga kependidikan, dan kepuasan layanan kerjasama diberikan kepada mitra kerjasama.

\section{Pengukuran Kepuasan Layanan Pendidikan pada Mahasiswa}

Pengukuran kepuasan layanan mahasiswa FSTT Undikma difokuskan pada lima aspek yaitu: (1) Keandalan (reliability): kemampuan dosen, tenaga kependidikan, dan pengelola dalam memberikan pelayanan; (2) Daya tanggap (responsiveness): kemauan dari dosen, tenaga kependidikan, dan pengelola dalam membantu mahasiswa dan memberikan jasa dengan cepat; (3) Kepastian (assurance): kemampuan dosen, tenaga kependidikan, dan pengelola untuk memberi keyakinan kepada mahasiswa bahwa pelayanan yang diberikan telah sesuai dengan ketentuan; (4) Empati (empathy): kesediaan/kepedulian dosen, tenaga kependidikan, dan pengelola untuk memberi perhatian kepada mahasiswa; (5) Kepastian (assurance): kemampuan dosen, tenaga kependidikan, dan pengelola untuk memberi keyakinan kepada mahasiswa bahwa pelayanan yang diberikan telah sesuai dengan ketentuan. Angket disusun dalam 27 pertanyaan positif dengan jawaban berdegradasi menggunakan skala likert, yaitu SB (Sangat Baik), B (Baik), C (Cukup), K (Kurang). Analisis data tingkat kepuasan layanan pendidikan dilakukan secara deskriptif dengan dengan mengeksplorasi tingkat kepuasan mahasiswa terhadap aspek Keandalan (Reliability), Daya Tanggap (Responsiveness), Kepastian (Assurance), Empati (Empathy), dan Kepastian (Assurance). Data hasil pengukuran kepuasaan mahasiswa dianalisis menggunakan persentase mahasiswa yang menjawab/menyatakan Sangat Baik, Baik, Cukup, atau Kurang.

\section{Pengukuran Kepuasan Sumber Daya Dosen dan Tenaga Kependidikan}

Aspek-aspek tingkat kepuasan sumber daya dosen dan tenaga kependidikan FSTT Undikma yang diukur untuk responden dosen dan tenaga kependidikan adalah sama, yaitu kepuasan pada pekerjaan (tugas), kepuasan kepada pimpinan, kepuasan pada sistem dan alur informasi, kepuasan pada suasana kerja, dan kepuasan pada kompensasi. Instrumen pengukuran tingkat kepuasan dosen dan tenaga kependidikan adalah Kuesioner Pengukuran Tingkat Kepuasan. Instrumen kepuasan terdiri dari 5 item. Skor pernyataan dalam instrumen kuesioner ini terdiri atas pernyataan kepuasan dalam skala 1-5. Nilai skala kepuasan 1, adalah nilai terendah dari rentang nilai kepuasan yang ada, artinya responden tidak puas dengan pelayanan yang diberikan oleh FSTT Undikma. 
Sedangkan nilai tertinggi adalah 5, artinya responden merasa sangat puas dengan aspekaspek pelayanan yang diberikan oleh FSTT Undikma selama ini.

\section{Pengukuran Kepuasan Mitra}

Tingkat kepuasan mitra (mitra kerjasama FSTT Undikma) diukur menggunakan angket (kuesioner) dengan identitas karakteristik mitra, dan tingkat kepuasan mitra dalam pelaksanaan kerjasama. Sebagai sample adalah mitra kerjasama prodi pendidikan Fisika FSTT Undikma. Tingkat kepuasan, yaitu: 5 (sangat puas); 4 (puas); 3 (cukup puas); 2 (kurang puas); 1 (tidak puas). Mitra mengisi kuesioner pada aspek: 1) Tanggungjawab kerjasama, 2) Iklim kerjasama, 3) Tanggap terhadap segala bentuk kegiatan yang melibatkan mitra, 4) Komunikasi dalam kerjasama, 5) Kemanfaatan kerjasama, 6) Ketepatan waktu dalam setiap agenda kegiatan dalam kerjasama, 7) Kesesuaian hasil kerjasama dengan hasil yang diharapkan mitra.

\section{HASIL DAN DISKUSI}

Hasil pengukuran tingkat kepuasan mahasiswa terhadap layanan pendidikan di FSTT Universitas Pendidikan Mandalika ditabulasi sebagaimana disajikan pada Tabel 1.

Tabel 1. Hasil pengukuran kepuasan mahasiswa

\begin{tabular}{lcccc}
\hline \multirow{2}{*}{ Aspek } & \multicolumn{4}{c}{ Tingkat Kepuasan (\%) } \\
\cline { 2 - 5 } & Sangat Baik & Baik & Cukup & Kurang \\
\hline Reliability & 77,59 & 13,28 & 5,81 & 3,32 \\
Responsiveness & 76,35 & 14,52 & 6,64 & 2,49 \\
Assurance & 80,08 & 12,03 & 6,22 & 1,66 \\
Empathy & 82,16 & 11,62 & 4,98 & 1,24 \\
Assurance & 73,03 & 14,52 & 7,88 & 4,56 \\
\hline
\end{tabular}

Berdasarkan data pada Tabel 1 dapat dijelaskan bahwa rata-rata skor tingkat kepuasaan mahasiswa terhadap layanan pendidikan yaitu: a) Aspek Keandalan (Reliability) yang menjawab Sangat Baik sebesar 77,59\%, Baik sebesar 13,28\%, Cukup sebesar 5,81\%, Kurang 3,32\%. b) Aspek Daya Tanggap (Responsiveness) yang menjawab Sangat Baik sebesar 76,35\%, Baik sebesar 14,52\%, Cukup sebesar 6,64\%, Kurang 2,49\%. c) Aspek Kepastian (Assurance) yang menjawab Sangat Baik sebesar 80,08\%, Baik sebesar 12,03\%, Cukup sebesar 6,22\%, Kurang 1,66\%. d) Aspek Empati (Empathy) yang menjawab Sangat Baik sebesar 82,16\%, Baik sebesar 11,62\%, Cukup sebesar 4,98\%, Kurang 1,24\%. e) Aspek Kepastian (Assurance) yang menjawab Sangat Baik sebesar $73,03 \%$, Baik sebesar 14,52\%, Cukup sebesar 7,88\%, Kurang 4,56\%. Data kepuasan mahasiswa tersebut ditegaskan kembali pada Gambar 1.

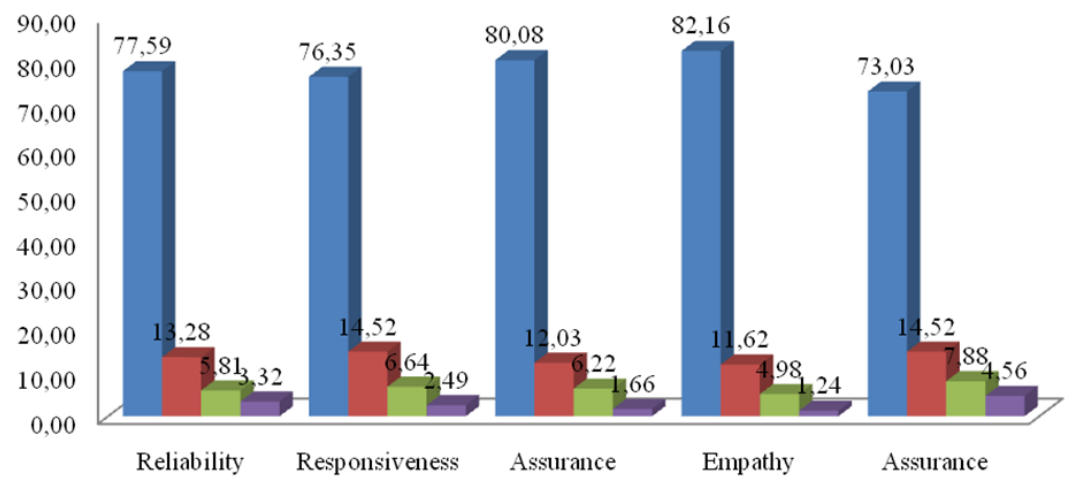

Gambar 1. Hasil kepuasan mahasiswa 
Berdasarkan hasil pengukuran, maka direkomendasikan beberapa hal sebagai berikut, yaitu layanan pendidikan pada aspek Keandalan (Reliability), diperlukan adanya kegiatan pelatihan dan workshop untuk meningkatkan kompetensi dosen, tenaga kependidikan, dan pengelola unit di lingkungan FSTT Universitas Pendidikan Mandalika agar dapat memberikan pelayanan yang maksimal. Layanan pendidikan pada aspek Daya Tanggap (Responsiveness), diperlukan adanya kegiatan untuk meningkatkan motivasi dan kesadaran kolektif dari dosen, tenaga kependidikan, dan pengelola unit di di lingkungan FSTT Universitas Pendidikan Mandalika untuk melayani dan membimbing mahasiswa dengan resposibilitas yang baik. Layanan pendidikan pada aspek Kepastian (Assurance) diperlukan adanya kegiatan pelatihan kepemimpinan dan manajemen bagi dosen, tenaga kependidikan, dan pengelola unit di lingkungan FSTT Universitas Pendidikan Mandalika agar dapat memberikan keyakinan kepada mahasiswa bahwa pelayanan yang diberikan telah sesuai dengan ketentuan yang berlaku. Layanan pendidikan pada aspek Empati (Empathy) diperlukan adanya peningkatan intensitas kegiatan keagaamaan untuk meningkatkan rasa empati dan kepedulian dari dosen, tenaga kependidikan, dan pengelola unit di lingkungan FSTT Universitas Pendidikan Mandalika dalam memberikan pelayanan. Layanan pendidikan pada aspek Kepastian (Assurance) diperlukan adanya peningkatan pengadaan sarana dan prasarana secara spesifik sesuai kebutuhan unit layanan di lingkungan FSTT Universitas Pendidikan Mandalika.

Selanjutnya, hasil pengukuran kepuasan sumber daya dosen dan mahasiswa seperti disajikan pada Gambar 2 dan Tabel 2.

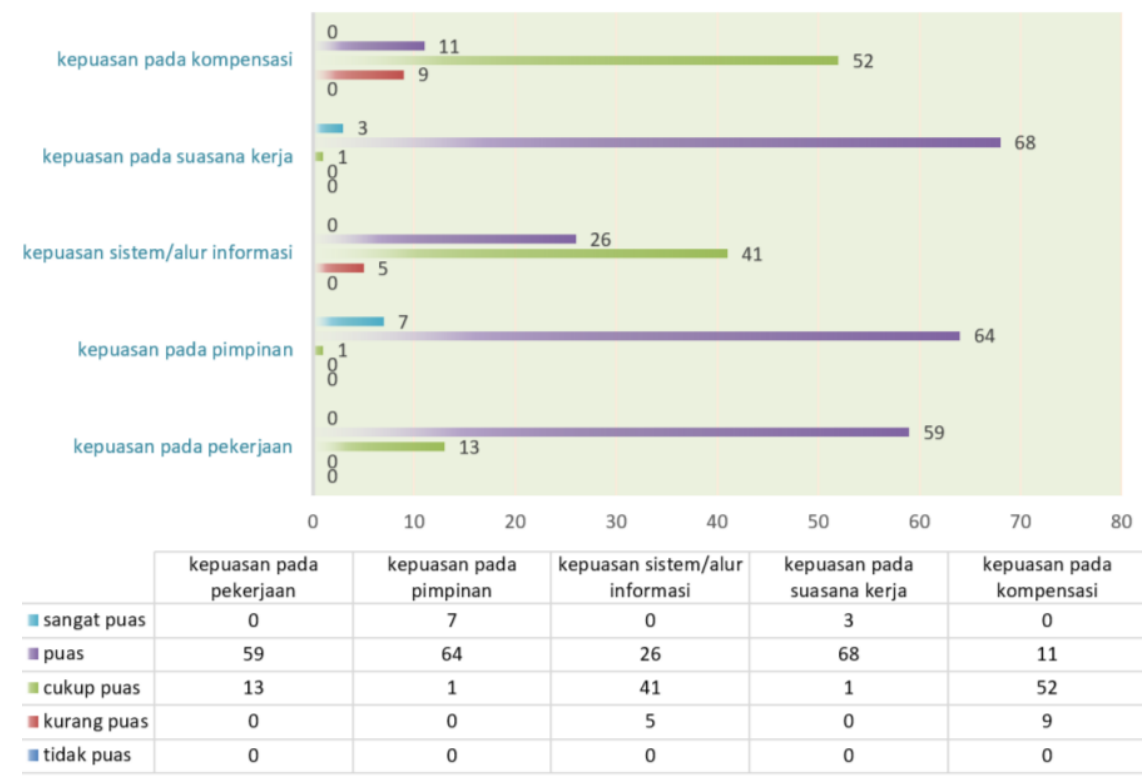

Gambar 2. Hasil pengukuran kepuasan

Tingkat kepuasan sumber daya dosen dan tenaga kependidikan di FSTT Undikma telah diukur, hasil telah disajikan seperti pada Tabel 2. Sebanyak 72 responden terlibat dalam survey. Kepuasan paling menonjol pada suasana kerja, dimana pada kategori ini tingkat kepuasan sangat tinggi pada kategori puas. Ini diikuti pada aspek kepuasan pada pimpinan dan pada pekerjaan (tugas). Namun demikian, kategori cukup puas paling banyak terdistribusi pada aspek kepuasan pada kompensasi dan kepuasan sistem/alur informasi, dan kedua aspek ini juga mendapat respon yang kurang puas dari SDM dosen dan tenaga kependidikan. Kriteria tiap aspek kepuasan disajikan pada Tabel 3. 
Tabel 3. Kriteria tiap aspek kepuasan

\begin{tabular}{llcc}
\hline No & Aspek & Skor rata-rata & Kriteria \\
\hline 1 & kepuasan pada pekerjaan & 3,81 & Puas \\
2 & kepuasan pada pimpinan & 4,10 & Puas \\
3 & kepuasan sistem/alur informasi & 3,32 & Cukup puas \\
4 & kepuasan pada suasana kerja & 4,03 & Puas \\
5 & kepuasan pada kompensasi & 3,07 & Cukup puas \\
\hline & Rata-rata & 3,66 & Puas \\
\hline
\end{tabular}

Hasil pada Tabel 3 menunjukkan skor rata-rata kepuasan SDM dosen dan tenaga kependidikan sebesar 3,66 berkriteria puas. Walaupun secara rata-rata berkriteria puas, hanya saja pada aspek kepuasan sistem/alur informasi dan kepuasan pada kompensasi keduanya berkriteria cukup puas.

Hasil survey menunjukkan kepuasan SDM dosen dan tenaga kependidikan pada aspek kepuasan pekerjaan, pimpinan, dan suasana kerja (ketiganya berkriteria puas). Sedangkan pada aspek sistem/alur informasi dan kompensasi berkriteria cukup puas, bahkan pada kedua aspek ini ditemukan respon kurang puas. Sebagai rekomendasi dari hasil ini maka perlu dilakukan perbaikan untuk mendukung kinerja pelayanan FSTT agar lebih baik dari masa ke masa, serta dapat memberikan kepuasan yang optimal pada pemangku kepentingan khususnya SDM dosen dan tenaga kependidikan.

Selanjutnya, pelaksanaan evaluasi pemanfaatan dan kepuasan hasil kerjasama dilakukan melibatkan 18 responden mitra kerjasama. Hasil menunjukkan rata-rata kepuasan pada kriteria puas dan sangat puas. Sebesar $66.67 \%$ dari institusi/lembaga yang sudah bekerjasama menyatakan puas telah bekerjasama. Hasil ini tentunya akan menjadi rencana tindak lanjut pada kegiatan kerjasama agar dapat dilanjutkan/diperpanjang selagi kemanfaatannya telah dirasakan oleh kedua belah pihak, antara mitra dengan FSTT Undikma.

\section{KESIMPULAN}

Studi eksplorasi kepuasan pemangku kepentingan pada layanan manajemen kelembagaan di Fakultas Sains, Teknik, dan Terapan, (FSTT) Universitas Pendidikan Mandalika telah dilakukan. Pemangku kepentingan yang terlibat adalah pihak internal (dosen, mahasiswa, dan tenaga kependidikan), sedangkan eksternal adalah mitra kerjasama kelembagaan. Hasil studi telah menunjukkan kepuasan layanan mahasiswa secara umum berkategori sangat baik, kepuasan sumber daya dosen dan tenaga kependidikan berkategori puas, dan kepuasan mitra kerjasama berkategori puas. Ini tentu menjadi bahan evaluasi bagi FSTT Undikma untuk terus mempertahankan layanan manajemen kelembagaan agar tetap memberikan yang terbaik bagi pemangku kepentingan untuk keberlanjutan di masa-masa mendatang. Selanjutnya, aspek-aspek yang kurang perlu dilakukan perbaikan.

\section{REFERENSI}

Arambewela, R. \& Hall, J. (2009). An empirical model of international student satisfaction, Asian Pacific Journal of Marketing and Logistics, 21(4), 555-569.

Arokiasamy, A. \& Abdullah, A. (2012). Service quality and students' satisfaction at higher learning institutions: A case study of Malaysian university competitiveness. International Journal of Management and Strategy, 3(5), 1-16. 
Dib, H. \& Alnazer, M. (2013). The impact of service quality on student satisfaction and behavioral consequences in higher education services. International Journal of Economy, Management and Social Sciences, 2(6), 285-290.

Firdaus, A. (2006). The development of HEdPERF: A new measuring instrument of service quality for the higher education sector. International Journal of Consumer Studies, 30(6), 569-581.

Firdaus, A., (2005). HEdPERF versus SERVPERF: The quest for ideal measuring instrument of service quality in higher education sector. Quality Assurance in Education, 13(4), 305-328.

Goetsch, D. L., \& Davis, S. B. (2013). Quality management for organizational excellence: Introduction to total quality. USA: Pearson Education, Inc.

Govender, J. P., Veerasamy, D. \& Noel, D.T. (2012). International students' expectations and perceptions of service quality: The case of a higher education institution in South Africa. Journal of Economics and Behavioural Studies, 4(10), 588-594.

Hanaysha, J., Abdullah, H. \& Warokka, A. (2011). Service quality and students' satisfaction at higher learning institutions: The competing dimensions of Malaysian universities' competitiveness. Journal of Southeast Asian Research, 1-11.

Hansemark, O. C. \& Albinson, M. (2004). Customer satisfaction and retention: The experiences of individual with employees. Managing Service Quality, 14(1), 40-57.

Hasan, H. F. A., Ilias, A., Rahman, R. A., \& Razak, M. Z. A. (2009). Service quality and student satisfaction: A case study at private higher education institutions. International Business Research, 1(3), 163-175.

Johnstone, D. B. (2009). Worldwide trends in financing higher education. In Financing access and equity in higher education, Jane Knight (Ed.) Rotterdam, Taipei, Sense Publishers.

Karami, M. \& Olfati, O. (2012). Measuring service quality and satisfaction of students: a case study of students' perception of service quality in high-ranking business schools in Iran. African Journal of Business Management, 6(2), 658-669.

Lee, Y. J. J., Tai, D. W., \& Wang, R. (2012). An investigation of evaluative criteria for uncertainty reduction in overseas learning. International Journal of Technology and Engineering Education, 9(1), 1-10.

Prayogi, S., Yuanita, L. \& Wasis. (2018). Critical Inquiry Based Learning: A Model of learning to promote critical thinking among prospective teachers of physic. Journal of Turkish Science Education, 15(1), 43-56

Prayogi, S., Muhali, Yuliyansi, S., As'ary, M., Azmi, I., \& Verawati, N.N.S.P. (2019). The effect of presenting anomalous data on improving student's critical thinking ability. International Journal of Emerging Technologies in Learning, 14(6), 133-137.

Russell, M. (2005). Marketing education: A review of service quality perceptions among international students. International Journal of Contemporary Hospitality Management, $17(1), 65-77$.

Seng, E. L. K., \& Ling, T. P. (2013). A statistical analysis of education service quality dimensions on business school students' satisfaction. International Education Studies, 6(8), 136-146.

Tuan, N. (2012). Effects of Service Quality and Price Fairness on Student Satisfaction. International Journal of Business and Social Science, 3(19), 132-150.

UNESCO. (2014). Higher education in Asia: Expanding out, expanding up - The rise of graduate education and university research. Montreal, Canada: UNESCO.

World Bank. (2010a). International experience for assessing the quality of educational services at higher education institutions: A Policy note for the government of Poland. Washington DC: The World Bank. 
World Bank. (2010b). Financing higher education in Africa. Washington DC: The World Bank.

Yadav, J. I. (2012). Service quality towards student satisfaction: An empirical investigation in selected management institutions of Sangli City. Ninth AIMS International Conference on Management January 14, 2012. 